\title{
ESTIMASI KECEPATAN DAN PANJANG LARIAN LONGSOR BERDASARKAN PENDEKATAN LONGSOR ELM
}

\section{Estimates of Velocity and Slide Travel Distance using ELM Sliding Approach}

\author{
Matheus Souisa $^{1 *}$, Sisca M. Sapulete ${ }^{2}$, Sean O. Souisa ${ }^{3}$ \\ 1,2,3 Laboratorium Geosains Jurusan Fisika, FMIPA, Universitas Pattimura \\ ${ }^{1,2}$ Laboratorium Mitigasi Bencana Jurusan Fisika, FMIPA, Universitas Pattimura \\ ${ }^{1,2}$ Laboratorium Landslides Jurusan Fisika, FMIPA, Universitas Pattimura \\ Jln. Ir. M. Putuhena, Kampus Unpatti, Poka, Ambon, 97233, Indonesia \\ e-mail:1*thos.phys@gmail.com ; 2sisca_sapulete@yahoo.com; 3 seanomega9758@gmail.com \\ Corresponding author*
}

\begin{abstract}
Abstrak
Kegagalan lereng yang terjadi pada suatu lereng memiliki bidang gelincir pada struktur bawah permukaan sehingga dapat menimbulkan bencana longsor. Bencana ini terjadi di lokasi penelitian karena berada disekitar jalur patahan sehingga sebagian tanah mengalami retak dan longsor, karena disebabkan oleh hujan dengan durasi beberapa jam, sehingga tanah menjadi jenuh dan terlepas menggelincir mengikuti lereng dengan kecepatan yang tinggi dan panjang larian yang semakin jauh sampai mengendap. Hal inilah yang menyebabkan kerusakan dan kerugian, korban jiwa, pengungsian dan kerusakan lingkungan. Penelitian ini dilakukan di longsor Booi untuk menjelaskan perumusan model fisika dalam menentukan kecepatan dan panjang larian longsor menggunakan hukum kesetimbangan energi mekanik berdasarkan pada model lumped mass. Hasil analisis memberikan estimasi kecepatan maksimum $13.3 \mathrm{~m} / \mathrm{s}$ pada posisi $33.0 \mathrm{~m}$ berada pada elevasi 96.2 m.dpl dan panjang larian longsor $102.2 \mathrm{~m}$. Dengan demikian, semakin besar sudut kemiringan lereng terhadap sudut gesekan maka kecepatan longsor semakin tinggi dan panjang larian semakin besar. Alterasi kecepatan longsor sangat tergantung pada elevasi lereng dan jangkauan pengendapan material longsor.
\end{abstract}

Kata Kunci : Energi mekanik, estimasi kecepatan, longsor elm, panjang larian.

\begin{abstract}
Slope failure that occurs on a slope has a slip plane on the subsurface structure so that it can cause landslides. This disaster occurred in the research location because it was located around the fault line so that some of the soil was fractured and landslide. This disaster is caused by rain with a duration of several hours and is in a fault line, so that the soil becomes saturated and detached from slipping along the slope at a high speed and the length of the runway farther until it settles. This is what causes damage and loss, loss of life, displacement and environmental damage. This research was conducted in the Booi landslide to explain the formulation of a physics model in determining the speed and length of a landslide run using the law of mechanical energy equilibrium based on the lumped mass model. The results of the analysis provide an estimated maximum speed of $13.3 \mathrm{~m} / \mathrm{s}$ at position $33.0 \mathrm{~m}$ at the elevation of $96.2 \mathrm{~m} . d \mathrm{pl}$ and the length of the landslide runoff $102.2 \mathrm{~m}$. The profile model of speed estimation of the length of the Booi landslide run is similar to the velocity profile of the Elm landslide. Thus, the greater the slope angle to the friction angle, the higher the speed of the landslide and the longer the runaway length. Alteration of the speed of landslides depends largely on the slope elevation and the range of sedimentation of the landslide material.
\end{abstract}

Keywords: Mechanical energy, velocity estimation, elm landslide, travel distance. 


\section{PENDAHULUAN}

Bencana alam gerakan tanah (longsor) telah menarik banyak perhatian dari berbagai pihak karena hal ini merupakan salah satu bencana yang sering melanda daerah perbukitan dan pegunungan yang terjal di wilayah Pulau Ambon, terutama di musim hujan. Karena pada musim hujan terjadi alterasi tegangan permukaan dalam pori tanah dan menambah berat massa tanah akibat dari air yang meresap ke dalam tanah sehingga menyebabkan kegagalan lereng. Hal inilah yang menyebabkan kerusakan dan gangguan terhadap lokasi sekitar. Kerusakan yang ditimbulkan tidak hanya berdampak langsung seperti korban jiwa, kehilangan tempat tinggal, kerusakan fasilitas umum maupun lahan pertanian, tetapi berdampak tidak langsung pada kegiatan pembangunan dan aktivitas ekonomi di daerah bencana dan sekitarnya. Dengan besarnya dampak yang sering terjadi, maka diperlukan metode-metode estimasi dan data statistik kejadian longsor di Pulau Ambon serta kerugian yang ditimbulkan.

Penelitian ini bertujuan untuk menggambarkan karakteristik fisik longsor Booi berdasarkan data yang telah dilakukan oleh peneliti sebelumnya [3]. Data ini dikaji dengan menggunakan penggabungan model empirik dan model diskrit (lumped mass model) [5] dengan mempertimbangkan mekanisme dan penyebab gerakan massa longsor. Hasil kajian disajikan dalam bentuk nilai estimasi koefisien gesek semu, kecepatan dan jarak jangkauan longsor yang dapat dijadikan sebagai gambaran untuk evaluasi bahaya longsor di wilayah penelitian maupun dapat digunakan dalam mitigasi bencana gerakan tanah.

\section{METODE PENELITIAN}

Material penyusun lereng ketika terjadi perombakan atau hancur maka material tersebut akan bergerak mengikuti lereng atau bergerak ke arah bawah (downward) atau ke arah luar (outward) lereng. Hal ini dikenal sebagai gerakan tanah (mass movement) (Varnes, 1978 dalam [3]). Dengan kata lain gerakan tanah (longsoran) adalah perpindahan masa batuan/tanah karena pengaruh gaya berat. Hal inilah yang menyebabkan kerusakan infrastruktur dan lingkungan, korban jiwa dan kerugian harta benda yang cukup besar.

Secara umum, faktor penyebab utama terjadinya longsor di daerah penelitian adalah faktor alami dan non alami. Faktor alami yang memicu terjadinya longsor adalah tingginya tekanan air dalam pori tanahbatuan akibat curah hujan yang berkepanjangan, getaran yang diakibatkan oleh gempa bumi, pemotongan (undercutting) lereng menyebabkan erosi dan pembebanan tanah-batuan yang berlebihan di bagian atas lereng. Sedangkan faktor non alam adalah aktivitas pembangunan yang memotong lereng sehingga menjadikan lereng lebih curam, mengalihkan aliran air permukaan atau air tanah ke lokasi yang sebenarnya sudah mempunyai potensi longsor, penebang pohon ataupun vegetasi lainnya yang menyebabkan tingginya run-off air permukaan dan sengaja memodifikasikan landscape dengan membangun di lereng yang tidak stabil atau di jalur potensi longsor tanpa melakukan analisis kelerengan.

\subsection{Model Fisika Longsor}

Jika longsor debris mewakili massa dari slide potensial berupa lumped mass model. Lumped mass model merupakan model sederhana yang menganggap massa longsoran konstan sepanjang lintasan [1]. Gesekan diantara material longsor dan bidang gelincir akan menghambat penggelinciran dibawah beberapa sudut kemiringan kritis. Diatas sudut kritis percepatan massa mengikuti hukum kedua Newton. Jika massa material longsor memiliki energi potensial $H$ bergerak sejauh $x$ (Gambar 1), maka energi yang hilang selama pergerakan adalah:

$$
E_{f}=m g \int_{0}^{x} \cos \alpha \tan \phi_{p} \frac{d x}{\cos \alpha}
$$

dengan $m=$ massa bongkahan batuan $(\mathrm{kg}), g=$ percepatan gravitasi $\left(\mathrm{m} / \mathrm{s}^{2}\right), x=$ jarak horizontal $(\mathrm{m}), \alpha=$ sudut kemiringan lereng $\left({ }^{0}\right), \mu=$ koefisien gesekan dan $\phi_{\mathrm{p}}=$ sudut gesek semu $\left({ }^{0}\right)$. 


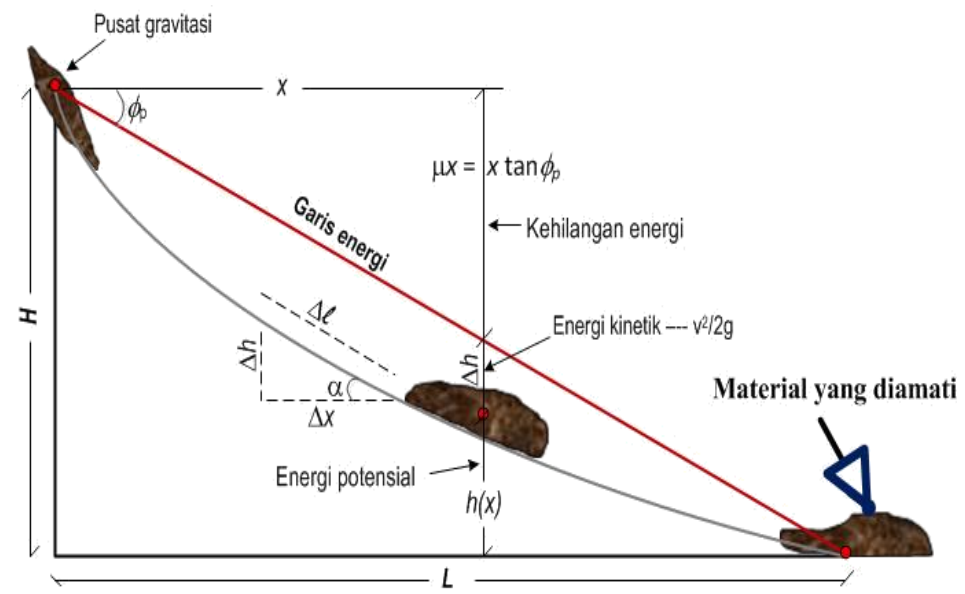

Gambar 1. Skema model geometri lereng yang digunakan untuk menghitung kecepatan dan jarak larian dari konsep garis energi (dimodifikasi dari [3])

Gambar 1 memperlihatkan energi ditunjukkan oleh tinggi (membagi energi dengan $m g$ ), garis energi menunjukkan energi total. $v^{2} / 2 g$ ditunjukkan oleh tinggi antara garis energi dan pusat gravitasi dari pergerakan massa [6]. Sudut $\phi_{\mathrm{p}}$ berhubungan dengan gradien garis energi. Oleh karena itu, longsoran berhenti dimana garis dari area sumber massa debris mulai meluncur dengan kemiringan $\phi_{\mathrm{p}}$ memotong permukaan topografi. Garis ini adalah garis energi. Dengan demikian, jika sudut $\phi_{\mathrm{p}}$ diketahui, jarak jangkauan dan kecepatan dapat diestimasi oleh gambaran garis energi.

Pada lokasi longsor dengan ketinggian $H$ bergerak massa debris di atas bidang gelincir sepanjang lintasan 1. Dengan meninjau elemen jarak $\Delta \ell$, bekerja gaya horizontal dan vertikal oleh reaksi sudut dan koefisien gesek. Dengan mengacu pada hukum kesetimbangan energi, menghasilkan:

$$
\Delta \frac{1}{2} m v^{2}=m g \sin \alpha \Delta \ell-\mu m g \cos \alpha \Delta \ell
$$

dengan $\sin \alpha \Delta l=\Delta h$ dan $\cos \alpha \Delta l=\Delta x$. Jika disederhanakan pers. (2), maka panjang larian longsor, menghasilkan:

$$
L=\frac{H}{\mu}=\frac{H}{\tan \phi_{p}}
$$

dengan $\mu=$ koefisien kekasaran permukaan lereng perbukitan atau tebing. Berdasarkan Gambar 1, posisi awal suatu massa debris terkandung energi potensial, massa ini mulai bergerak sepanjang lereng ada terjadi pergantian energi potensial menjadi energi kinetik, dan selama gelinciran terdapat energi yang hilang akibat gesekan $\left(E_{\mathrm{f}}\right)$. Disini energi rotasi tidak dipertimbangan demi penyederhanaan. Oleh karena itu, pada lokasi longsor dengan ketinggian $H$ bergerak massa debris di atas bidang gelincir sejauh $x$, maka mengacu pada hukum kekekalan energy [1,7] diberikan oleh

$$
m g H_{z}-m g h(x)=\frac{1}{2} m v(x)^{2}+m g x \mu
$$

Persamaan (4) disederhanakan untuk menghitung kecepatan longsoran di posisi $x$ :

$$
v(x)=\sqrt{2 g\left(H-h(x)-x \tan \phi_{p}\right)}
$$

Persamaan (5) menunjukkan bahwa jika $v(x)$ konstan, kemiringan topografi $\alpha=\phi_{\mathrm{p}}$. Apabila $\alpha>\phi_{\mathrm{p}}$ terdapat longsoran debris dipercepat, dan $\alpha<\phi_{\mathrm{p}}$ longsoran debris melambat [11].

Jika selama menggelincir dipertimbangkan rotasi, maka diasumsikan energi rotasi mewakili sekitar $5 \%$ dari energi kinetik bongkaan debris oleh Gerber (1994) [7], dan nilai $f_{v} \approx \sqrt{0.95}=0.97$, sehingga kecepatan longsor dari pers.(5), menghasilkan

$$
v(x)=f_{v} \sqrt{2 g \Delta h}=0.97 \sqrt{2 g \Delta h}
$$


Faktor $f_{\mathrm{v}}$ dapat ditentukan dengan menggunakan pengamatan lapangan untuk memperoleh lebih banyak estimasi presisi kecepatan translasi luncuran debris. Dan jika trayek longsoran debris menggelincir berupa garis lurus dengan kemiringan $\alpha$, kecepatan longsoran dihitung dengan rumus empiris oleh Masuya [7], menghasilkan

$$
v(x)=\chi \sqrt{2 g \Delta h}
$$

dengan $\chi=\sqrt{1-\frac{\mu}{\tan \alpha}}$ adalah koefisien garis lurus.

\subsection{Lokasi Penelitian}

Penentuan $v(x)$ dan $L$ didasarkan pada geometri longsor dalam pengamatan lapangan, dan untuk itu diambil longsor Booi di Kamp. Booi Kelurahan Batu Gadjah Ambon [4,8]. Letak longsor pada koordinat $03^{0} 42^{\prime} 24.2^{\prime \prime} \mathrm{s} / \mathrm{d} 03^{0} 42^{\prime} 22.9^{\prime \prime}$ LS, dan 128 $11^{\prime} 11.0^{\prime \prime} \mathrm{s} / \mathrm{d} 128^{0} 11^{\prime} 12.8^{\prime \prime}$ BT (Gambar 2). Secara umum topografi disekitar lokasi longsor berupa perbukitan bergelombang dengan ketinggian lebih dari $110 \mathrm{~m} . \mathrm{dpl} .$. Berdasarkan Gambar 2, batuan penyusun daerah longsor Booi terdiri batuan gunung api Ambon, yang terdiri dari tuff dan breksi gunung api. Daerah bencana lokasi longsor dan sekitarnya termasuk zona potensi terjadi bahaya longsor tinggi [9].

Model geometri lereng longsor diperoleh dari penelitian sebelumnya [3], dimana panjang garis energi $102 \mathrm{~m}$, lebar rata-rata tanah longsor $40 \mathrm{~m}$, dengan lebar terbesar $65 \mathrm{~m}$ di bagian tengah. Elevasi mahkota longsor 125 m.dpl dan kaki longsor adalah masing-masing $64 \mathrm{~m} . d p l$, dengan kemiringan yang terjal. Longsor Booi tergolong tipe slide rotasi dan longsor debris dengan ketinggian $10.5 \mathrm{~m}$ dengan panjang longsor menutupi pemukiman penduduk dan sungai.

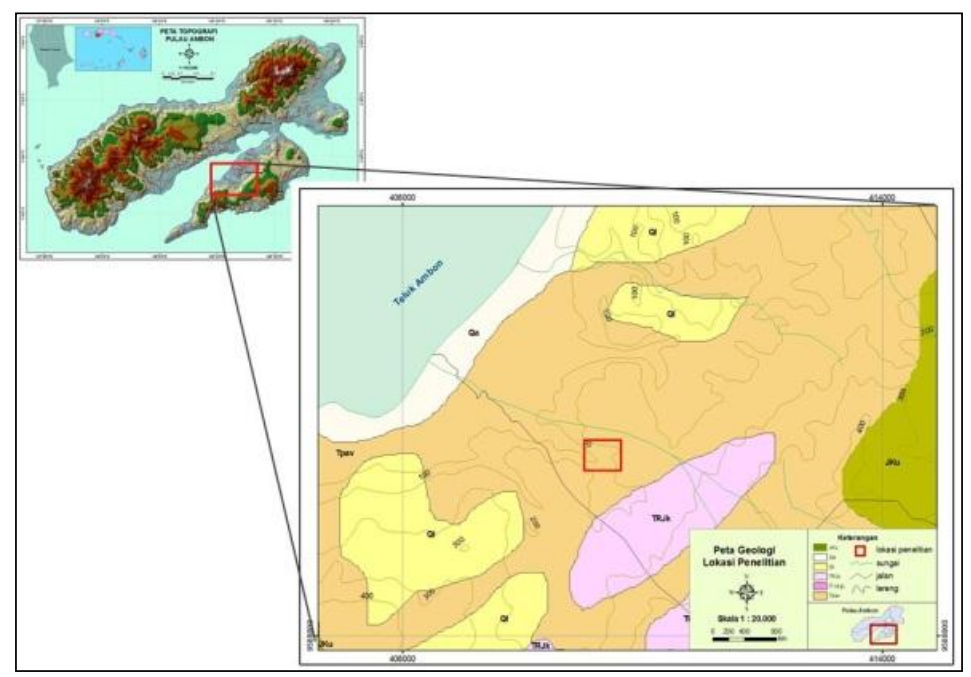

Gambar 2. Peta geologi lokasi longsor Booi

\section{HASIL DAN PEMBAHASAN}

Pada umumnya massa longsor yang bergerak pada bidang gelincir diakibat oleh adanya gaya tarik gravitasi bumi dan komponen gaya berat yang sejajar permukaan bidang miring. Pada daerah telitian, komponen-komponen ini berasal dari batuan yang lapuk dan mudah luruh jika terkena air hujan, banyaknya air hujan yang meresap ke dalam tanah akibat curah hujan yang tinggi dengan durasi lama serta pepohonan besar dan pemukiman berada diatas maupun disamping lereng. Oleh karena permukaan bidang miring kasar, maka terdapat gaya gesekan yang arahnya berlawanan dengan arah gerakan luncuran massa longsor.

Setelah dilakukan pengukuran parameter longsor pada volume massa tanah yang tidak stabil yang dilengkapi dengan jarak $(x)$ kelengkungan pada pusat massa longsor dan ketebalan busur longsor, tahapan berikut membuat lintasan lereng berdasarkan hasil pengukuran dan data parameter lereng. Data inilah yang digunakan untuk menentukan estimasi kecepatan dan panjang jangkauan longsor Booi berdasarkan 
persamaan-persamaan sebelumnya dan merujuk pada longsor Elm [1]. Estimasi kecepatan longsor hanya dilakukan pada satu slide rotasi sepanjang lintasan. Perhitungan kecepatan longsoran Booi, diawali dengan lintasan pertama $x=0$ dan pada lintasan kedua diambil $x=33.0 \mathrm{~m}$ (dianggap pusat massa longsor bergerak di titik ini) sesuai sudut kemiringan lereng $\alpha=41.25^{\circ}$. Hasil perhitungan untuk lintasan pertama menghasilkan persamaan

$$
v(x)=2.33 \sqrt{x}
$$

dan untuk lintasan kedua

$$
v(x)=\sqrt{262.91-2.58 x}
$$

Hasil perhitungan dengan menggunakan pers. ( 8 dan 9) dan dilanjutkan pers. (6 dan 7) sebagai fungsi dari jarak $(x)$ diperlihatkan dalam Gambar 3, sehingga dapat diestimasi kecepatan maksimum longsoran yang diperoleh berdasarkan lintasan memotong kedua kurva (slope break) di jarak yang telah ditentukan sehingga menyerupai longsor Elm. Hasil estimasi parameter secara keseluruhan disajikan pada Tabel 1.

Hasil analisis diperoleh estimasi kecepatan longsor maksimum $13.3 \mathrm{~m} / \mathrm{s}$ pada posisi $33.3 \mathrm{~m}$ yang berada pada elevasi maksimum 95.2 m.dpl. Hal ini menunjukkan bahwa turunan dari kecepatan terhadap posisi $x$ tidak terbatas pada titik awal dan akhir lintasan, yang berarti bahwa kecepatan berubah sangat cepat di sekitar titik-titik lintasan ini. Jadi, menurut analisis fisika longsor sederhana ini, longsoran berhenti tibatiba dan selanjutnya mendorong material yang ada di depannya untuk bergerak menuruni lereng.

Tabel 1. Hasil estimasi parameter longsor Booi

\begin{tabular}{|lrr|}
\hline \multicolumn{1}{|c}{ Parameter } & Nilai & Satuan \\
\hline Tinggi mahkota longsor, $H$ & 125.0 & m.dpl \\
\hline Sudut gesekan, $\phi$ & 30.9 & derajat \\
\hline Koefisien gesek, $\mu$ & 0.6 & \\
\hline Sudut kemiringan lereng, $\alpha$ & 41.2 & derajat \\
\hline panjang jangkauan $($ runout $)$ & 102.2 & $\mathrm{~m}$ \\
\hline Kecepatan maksimum, $v(x)_{\max }$ & 13.3 & $\mathrm{~m} / \mathrm{s}$ \\
\hline Jarak $(x)$ di $v(x)_{\max }$ & 33.0 & $\mathrm{~m}$ \\
\hline Elevasi $H(x)$ di $v(x)_{\max }$ & 96.2 & $\mathrm{~m} . \mathrm{dpl}$ \\
\hline Beda tinggi $\Delta h$ pada $v(x)_{\max }$ & 9.2 & $\mathrm{~m}$ \\
\hline$v(x)_{\max }($ Gerber $)$ & 13.0 & $\mathrm{~m} / \mathrm{s}$ \\
\hline$v(x)_{\max }$ (Masuya) & 8.5 & $\mathrm{~m} / \mathrm{s}$ \\
\hline
\end{tabular}

Estimasi kecepatan longsor perhitungan secara analitik dibandingkan dengan empiris (Gerber) mencapai $6.8 \%$. Nilai persentase ini menunjukkan bahwa massa longsor bergerak mengikuti lereng dengan energi kinetik total, dan kecepatan longsor menurut Gerber lebih kecil dari hasil analitik karena memperhitungkan faktor translasi dan rotasi. Sedangkan untuk estimasi kecepatan longsor menurut Masuya jauh lebih kecil dari estimasi kecepatan longsor secara analitik dan Gerber, karena diduga mempertimbangkan faktor tanah bercampur dengan air hujan. Dalam keadaan ini kecepatannya lebih kecil dengan perbandingan sebesar $36.1 \%$. Jadi kecepatan longsor tinggi apabila kondisi tanah-batuan dalam keadaan tidak basah, sedangkan kecepatan longsor rendah jika kondisi tanah-batuan dalam keadaan basah dan terseret oleh air hujan. Dengan demikian estimasi kecepatan longsor perhitungan hampir mendekati dengan rumusan empiris yang dikemukakan oleh Gerber. 


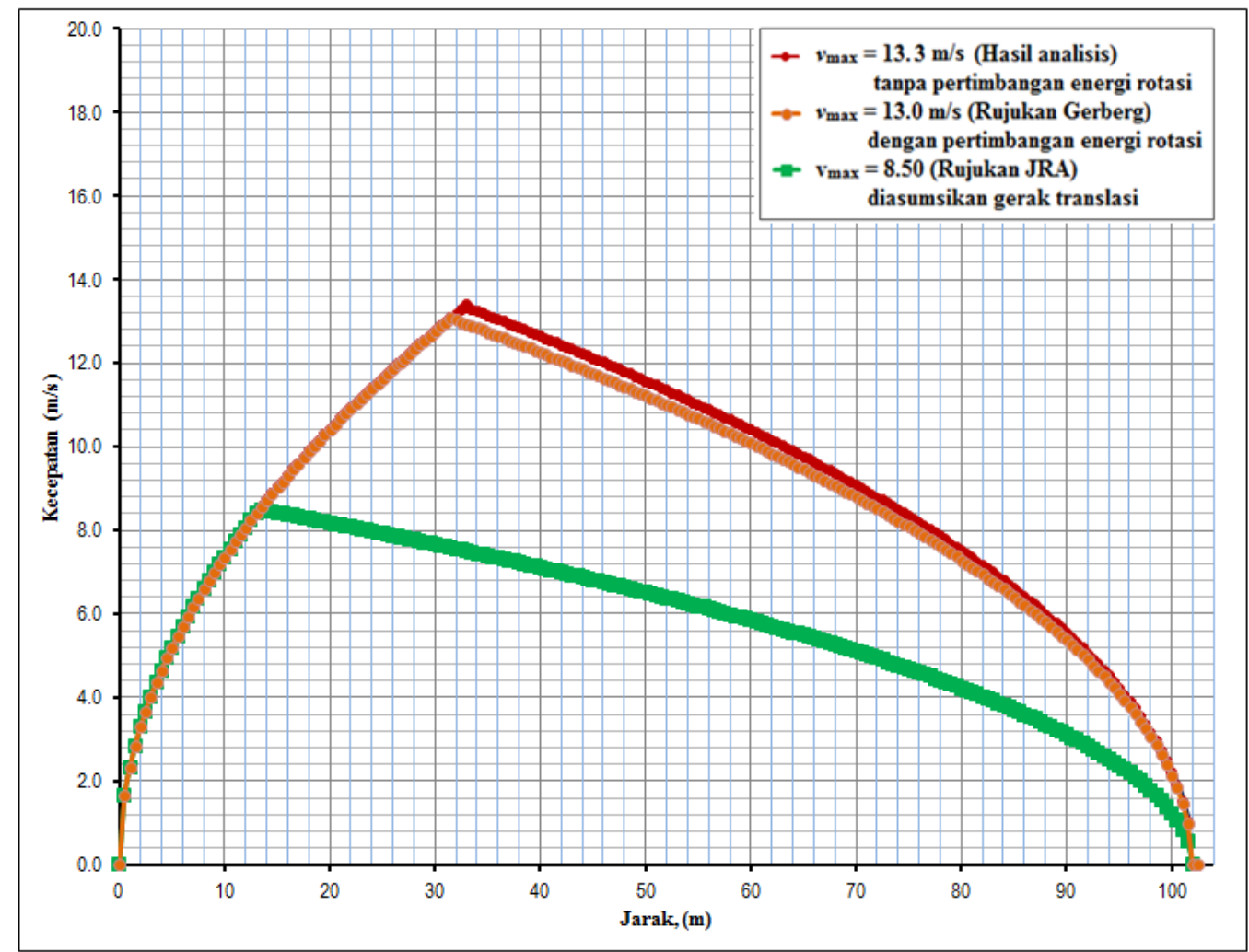

Gambar 3. Estimasi kecepatan longsor Booi (warna merah menunjukkan lintasan estimasi kecepatan longsor perhitungan, warna coklat menunjukkan lintasan estimasi kecepatan menggunakan rumusan Gerberg dan warna hijau adalah lintasan estimasi kecepatan menggunakan rumusan Masuya)

Hasil analisis, menunjukkan bahwa tipe batuan/tanah dan dimensi massa batuan yang tidak stabil dapat mempengaruhi kecepatan dan panjang larian longsor. Interpretasi litologi longsoran Booi berupa lempung pasiran bercampur kerikil, batuan ini memiliki kecepatan yang lebih cepat seperti yang laporkan oleh Hungr [10] dan jarak jangkauan (runout) lebih panjang dari pada jenis batuan lainnya [11]. Jadi kecepatan longsor tergantung pada sifat material dan karakteristik lereng. Keakuratan estimasi kecepatan dan panjang larian longsoran tergantung pada pengukuran geometri muka lereng longsor serta penentuan posisi pusat massa longsor dan penentuan besar sudut gesek semu. Oleh karena itu, hasil penelitian ini dapat dimungkinkan untuk evaluasi lereng, dan memprediksi perilaku longsor dan jarak larian untuk penilaian bahaya longsor, dengan mempelajari mekanisme yang menentukan hilangnya kekuatan energi pasca-kerusakan akibat longsor. Jadi, suatu langkah yang diusulkan untuk prevensi longsor Booi adalah dengan menggunakan model tol air yang dikombinasikan dengan bioengineering dan geoforestry.

\section{KESIMPULAN}

Berdasarkan analisis data longsor Booi, estimasi kecepatan dan panjang jangkauan hanya menggunakan geometri lereng dengan pendekatan model analitik dan empiris. Estimasi ini telah berhasil dilakukan, sehingga diperoleh kecepatan maksimum $13.3 \mathrm{~m} / \mathrm{s}$ di posisi $33.0 \mathrm{~m}$ yang berada pada elevasi maksimum 96.2 m.dpl. Nilai kecepatan longsor sangat tinggi berada pada bagian atas bidang retak dan membawa energi besar hingga mengecil mengikuti kelerengan dengan panjang jangkauan $102.2 \mathrm{~m}$.

\section{DAFTAR PUSTAKA}

[3] F. V. de Blasio, "Introduction to the Physics of Landslides", Springer Science+Business Media, New York, B.V. 2011.

[7] H. Masuya, History And Highlights Of Rock Fall Research In Japan, Interdisciplinary Workshop on Rockfall Protection, Morschach, 2008. 
[4] K.Sassa, "Geotechnical Model for the Motion of Landslides", In Proceedings of the $5^{\text {th }}$ International Symposium on Landslides, Lausanne, Switzerland, Edited by C.Bonnad, Vol.1.A.A., Balkema Rotterdam, The Netherlands, 1988.

[1] M.Souisa, L.Hendrajaya dan G. Handayani, "Pencitraan Resistivitas Bidang Longsor di Perbukitan Booi dan Erie Kota Ambon Menggunakan Konfigurasi Wenner-Schlumberger", Spektra: Jurnal Fisika dan Aplikasinya, UNJ, Jakarta, Vol.16, No.2, Oktober 2015.

[2] M. Pastor and L.Picarelli, "Recommendations for runout models for use in landslide hazard and risk mapping", SafeLand, 7th Framework Programme Cooperation Theme 6 Environment (including climate change) SubActivity 6.1.3 Natural Hazards, Deliverable 1.9, 2010.

[5] M. Pirulli, "Numerical Modeling of Landslide Runout (A continuum mechanics approach)", Politecnico Di Torino, Department of Structural and Geotechnical Engineering, 2005.

[6] M. Jaboyedoff, and V.Labiouse, "Technical Note: Preliminary Estimation of Rockfall Run-out Zones", Nat. Hazards Earth Syst., Sci. 11, 2011.

[8] M.Souisa, L.Hendrajaya and G.Handayani, "Determination of Landslide Slip Surface Using Geoelectrical Resistivity Method at Ambon City Moluccas Indonesia", Jurnal Internasional, IJTAE, Volume 5, Issue 7, July 20, 2015.

[9] M.Souisa, L.Hendrajaya and G.Handayani, "Landslide Hazard and Risk Assessment for Ambon City Using Landslide Inventory and Geographic Information System", Journal of Physics: Conference Series 739, 2016.

10] O.Hungr, J.Corominas and E. Eberhardt, "Estimating landslide motion mechanism, travel distance and velocity", Proceedings of the International Conference on Landslide Risk Management, Vancouver, Canada, May-June. 2005.

[11] M.Souisa, L.Hendrajaya and G.Handayani, Study on Estimates of Travel Distance, "Velocity and Potential Volume of Amahusu Sliding Plane using Energy Conservation Approach in Conjunction with Geoelectric Survey", Journal of Mathematical and Fundamental Sciences, Vol. 50, No. 2, 2018. 
